\title{
Employee Performance Management at a South African Government Organization
}

\author{
Saajida Khan \\ Wilfred I. Ukpere \\ Department of Industrial Psychology and People Management, Faculty of Management, \\ University of Johannesburg, Johannesburg, South Africa \\ E-mail: wikpere@uj.ac.za
}

\section{Doi:10.5901/mjss.2014.v5n3p661}

\section{Abstract}

Performance Management is a process by which the outputs of employees are measured and controlled in order to improve organisational effectiveness and reward employees accordingly. The objective of this study was to determine the effects of Performance Management, inclusive of its policies; administration processes and systems on employees and determine how to optimize its current status at a South African Government Organization. Face-to-face interviews and performance management compliance audits were conducted with all Line Managers and a sample of employees in order to determine its impacts on employees and the management of their performance. It has been found that gaps exist in terms of understanding the use of the electronic performance management system, compliance to performance management policy \& timelines, pertinent feedback from management with regard to development areas, and a lack of training initiatives to address training needs in order develop organisational effectiveness \& employee morale. It is recommended that mechanisms are initiated such as information sharing sessions, feedback timelines and training plans in order to address these challenges effectually.

Keywords: Performance Management, current status, impacts, challenges.

\section{Introduction and Background}

Performance Management governs the outputs of individuals and teams within the organization in line with organisational strategy and objectives.

Performance Management processes are not stand alone systems, these work in conjunction or feed into various other company processes such as compensation systems, recruitment and selection, job profiling, talent management, benchmarking, etc (Grobler, Warnich, Carrell, Elbert, Hatfield, 2006). In order for these processes to be effectively influenced or affected by performance management, the process must be qualitatively sound and smoothly run (Nel, Werner, Du Plessis, Ngalo, Poisat, Sono, Van Hoek, \& Botha, 2013).

The organization under study comprises of approximately 15000 permanent employees. There are over 200 offices country-wide. It has a significant footprint in each of the 9 South African Provinces. A sub-division of the organization is used for the purpose of this research which comprises of approximately 630 full-time employees nationally, of which 220 are based in Gauteng. The primary source of data is gathered from the research conducted in the Gauteng region.

Performance Management within the organization is governed by the internal "Employee Performance Management (EPM)" policy. EPM is a recently revised/updated policy which was previously titled the "Performance Management \& Development System (PMDS)" policy. The organisation uses an online system called ePMS: electronic Performance Management System that is structured according to the EPM policy.

The policy is clear and concise in outlining its principles, processes and objectives, however, the extent to which these are followed differ between managers and employees respectively within the organization. In light of the above, the administering of the policy and processes that are followed in this regard impact employees and their behaviours in various ways.

As per the policy, performance reviews are conducted on a quarterly basis (every 3 months). The review entails a basic overview of performance for the period, between manager and employee. This process forms part of chain, which aids in determining whether employee performance requires development, is acceptable or outstanding. Interim reviews and appraisals are allowed as frequently as possible to assist managers in managing performance successfully and allow employees the opportunity for continued development (Noe, Hollenbeck, Gerhart, \& Wright, 2013). 
Employee performance is measured by an online measurement tool called the scorecard, which is accessible on the electronic Performance Management System (ePMS). The scorecard comprises of Strategic Performance Objectives (SPOs) - broad objectives \& Key Performance indicators (KPIs) - sub objectives. Each employee is required to have at least 2 SPOs. Each SPO has specific score linked to it; the total weighting of objectives is $100 \%$. The total percentage achieved by the employee on the scorecard is used in a ranking system do determine the performance bonus received by the employee at financial year-end (Nel, van Dyk, Haasbroek, Schultz, Sono, T., \& Werner, 2004).

The scorecard is specific to a group of jobs performed by employees within the organisation, although it may be specialised if an employee has a diverse focus or additional responsibilities. A Personal Development Plan (PDP) ties into the process of performance management by allowing managers and employees the opportunity to document development areas and plan a way forward in order to address them (Rao, 2009). Personal Development Plans must be updated on a continuous basis in order to be used effectively. Scorecards and PDPs of employees are to be filed and signed by both employee and manager (Rao, 2005). The ePM System is aimed at creating a simplified process of measuring performance. Timelines are developed for review and appraisal processes in order to structure compliance.

The organisations principles of performance management include shared ownership, responsibility \& accountability; linking individual performance objectives to business plans and goals; accurately set targets; providing effective \& timeous feedback etc. These principles are as far as possible incorporated into the ePM system. Consistency in terms of application of Performance Management principles from region to region, between sub-divisions as well as teams within business units is of great significance and has considerable impacts on employees (Millmore, Lewis, Saunders, Thornhill, \& Morrow, 2007).

Effective management of performance, consistent application of performance management principles, as well as the follow through of performance management outcomes is a challenge to many. There are concerns with regard to the understanding the ePM system, adherence to ePM policy and timelines, feedback given to employees by management and training initiatives available that develop employees in order to improve performance within the organisation (Regis, 2008).

Identifying ways in which to optimise the current state of performance management within the organisation is the objective of this article. Creating awareness and understanding regarding ePMS, providing effective feedback and training employees in line with individual areas of development that influence their day-to-day jobs will aid in optimising the performance management status within the organisation.

\subsection{Problem Statement}

Performance Management plays a key role in ensuring the objectives and goals of the organisation are met. Performance Management is a function and responsibility of managers and employees that must be managed aptly in order to influence employees effectively. It is a sensitive, yet imperative component of organizational success measurement. In order to manage performance, the acceptable levels of performance, specific job requirements and assessment methods must be understood by employees and managers. Understanding the ePM system is also a requirement for effective performance management. Compliance in terms of ePM timelines is of great significance. Training and development initiatives must be available and followed through in terms of performance/skills gaps identified. Consistency in application and effective management of Performance Management processes and principles are imperative to its success. Achieving the desired effect on employees in order to meet the objectives of the organization is currently a Performance Management challenge.

\subsection{Research questions}

The above statement led to the following research questions:

- What is the importance of performance management?

- Is there an overall/universal process of performance management?

- If so, outline the process or provide alternatives

- What are the factors that influence performance management?

\subsection{Research Objective}

The objective of this research is to determine the effects of Performance Management in the case organisation, in order 
to find out ways of optimizing the current state of Performance Management within the organisation.

\section{Literature Review}

\subsection{Performance Management Conceptualised}

Performance Management, according to the organisation under study, performance management is defined as a continuous interactive process in order to attain high ranks of organisational performance by which contributions are made to the effective running of teams and individual employees. The system creates collective vision and understanding regarding targets and incorporates the training and development of employees in order to ensure these targets are achieved.

According to Jamil (2005) one of the most significant business requirements for organisational success is an effective performance management system, with specific reference to its operations. Kehinde (2012) mentions that performance management, coupled with talent management is one of the key drivers of any efficacious organisation. Miah and Hossan (2012) \& Walker (2007) argue that performance management assists in increasing the quantity and quality of work produced by employees and aligns it to organisational strategies. Armstrong and Baron (1998) claim that performance management will not meet high success levels if it's not aligned to the strategy of the organisation (Cited in Miah \& Hossan, 2012)

Performance management in organisations aids in identifying the potential of employees, growth rates and their competencies according to Jamil (2005). Fletcher and Williams (1998) mention that various organisations are attempting to integrate performance management into their culture in order to positively influence employee behaviour, in turn contributing to the success of the organisation as well as development of individuals within the organisation. This may be regarded as a two-fold or mutual benefit (Cited in Bayat 2011). Miah and Hossan (2012) mention that Armstrong (2006) emphasises the goal of performance management as creating and developing a culture of high performance where responsibility is taken for on-going improvement by employees and teams they form part of.

Communication is an integral part of any work environment. According to Bayat (2011) performance management is fashioned, developed and maintained in organisations in order to facilitate communication. Walker (2007) notes that performance management as the single greatest contributor to organisational efficacy. From the research conducted on the importance performance management it is evident that Walker assertion was right.

\subsection{The performance Management process}

From the literature review, it is clear that there is no universal process for PM; however an integrated use of different processes might outline a somewhat flexible and objective model - common processes range from four to eight stages, which is discussed below

\subsubsection{Step 1: Planning}

The planning step forms the initial part of most performance management process. It involves linking and aligning the strategy and objectives of the organisation to the performance management process (Cornell University, 2009) at large as well as to individual and team goals. The planning stage allows for the performance criteria to be established (Cornell University, 2009) and determines a way forward in terms of communication of the process to the organisation. During the planning stage, Jamil (2005) states that the performance management process is linked to a larger chain of HR processes such as promotion strategies, training initiatives, recruitment policies, rules for selection, reward allocations, etc. The planning stage is sometimes referred to as the agreement stage according to ets (2008).

\subsubsection{Step 2: Performance Observation}

Ryan (2013) mentions that the best way to fairly assess the work of an employee is to observe the employees performance. Observation allows the assessor/appraiser to be objective when assessing/appraising the employee. According to Ryan (2013) there are usually certain criteria that managers use when observing employee performance such as integrity, consistency, quality, consistency, ethics, timelines, safety, effort, etc. Ingram (2013) argues that managers should observe employees so discretely that employees are not aware of it, employees must not feel that they 
are being monitored as it might cause a modification in employee behaviour, whereas Stone (2006) argues that it is important that employees know when management are observing performance so as not to feel unusually monitored. Reviewing reports of employee performance, monitoring work-specific hindrances to the employees day-to-day job as well as having an objective criteria for observing an employee may all result in a more favourable performance observation according to Ryan (2013).

\subsubsection{Step 3: Performance Assessment/Review/Appraisal}

Deemed to be the central component of the performance management process by various authors, it is apparent that the performance appraisal stage is highly significant, yet sensitive in nature. According to Moore (2013), performance appraisal meetings are confidential and should be treated as such, the session essentially held in an enclosed and private area, preferably away from the usual place of work as this reduces stress levels of the employee. Balle (2013) mentions that most companies have self-assessment opportunities, with regard to their performance prior to the actual appraisal meeting. The performance appraisal "meeting should be a time for managers and employees to discuss and ask questions. Managers should share the positives balanced with the areas of improvement. Setting the goals for the next appraisal period is important, and following up to ensure that the goals are met is equally important" (Moore, 2013).

\subsubsection{Step 4: Performance Feedback}

According to Edenborough (2005, pp. 225) performance feedback is an integral component of performance management and the feedback given to employees must be precise to be effective (cited in Bann 2009). Miah and Hossan (2012) argue that time and resources are substantial in the performance management process, especially when providing feedback to employees.

Stone (2007) mentions that performance feedback is significant information conveyed to the employee that imposes which actions the employee should increase, which the employee should maintain and which actions should be stopped or reduced in terms of performance. Griffin (2013) mentions that constructive performance feedback honours good performance and allows poor performance of employees to be rectified. According to Stone (2007) \& Griffin (2013) performance feedback is an on-going process which should be maintained to reinforce the positive behaviours of employees. Griffin (2013) maintains that performance and the feedback given in that regard must always be aligned with performance standards. Balle (2013) argues that relevant and objective feedback strengthens the employer-employee relationship.

\subsubsection{Step 5: Recognition and Corrective measures}

Employee recognition is an essential component of the performance management process. It is one of the factors that may be deemed as a driving force for employee performance, given the circumstances are otherwise positive. Magill (2012), states that recognising employees leads to a boosted morale and increases productivity which is mutually beneficial. According to Macgill (2013) Employee rewards and recognition range from small to large scale, it is inclusive of but not limited to:

- Employee of the month certificates/awards,

- Long-service certificates,

- Shopping \& meal vouchers,

- Unspecified gifts, and

- Performance bonuses, etc.

Corrective measures include those activities associated with the management of poor performers within the organisation. Poor performance may be managed on an incentive basis, by coaching and mentoring and in some instances by disciplinary procedures according to Miah \& Hossan (2012)

\subsubsection{Step 6: Employee/ Career/ Organisational capability development}

According to Miah and Hossan (2012) training and development is the last yet deciding stage of the performance management process. It allows employees to be developed, competencies to be improved and the capability of the organisation to increase if carried out effectively and efficiently. It has a positive impact on employees if it aids in 
enhancing knowledge and performance.

\subsection{Factors influencing Performance Management}

There are various factors that influence performance management. Many of which are linked in some way. According to Bann (2009), performance management may result in positive results for the employee and employer if applied in the correct manner. Along with this Bann (2009) conducted an extensive literature review and identified four sections of factors that influence the performance management process and system. The four sections of factors as identified by Bann (2009) are as follows:

\subsubsection{Employee Factors}

Employee factors are various, inclusive of, but not limited to the following:

- Employee reactions to different situations,

- Confidence levels of individuals,

- Skills specific to jobs,

- Emotional intelligence levels,

- How the performance management system and process is perceived by the individual,

- The level of preparedness of employees for the performance appraisal process,

- How and what training and development needs are identified, etc.

\subsubsection{Management Factors}

Managerial factors are numerous, inclusive of, but not limited to the following:

- Have a clear understanding of the performance management process, system and purpose in the organisation,

- Understanding of people and what influences employees in the organisational context,

- To be an effective appraiser- thus possessing skills such as good listening skills, good verbal and non-verbal communication, questioning skills, and criticising - effective and non-harmful,

- Commitment to the process and system,

- Ability to analyse,

- A sound Knowledge base specific to the work the employee performance,

- Preparedness of manager for the performance appraisal process,

- Ability to have difficult discussions with employees whilst ensuring that the employee understands that it is purely work related,

- Ability to maintain objectivity,

- Integrity,

- Professional approach,

- Mentoring, coaching and counselling skills, etc.

\subsubsection{System Factors:}

There are several system factors, inclusive of, but not limited to the following:

- The purpose of performance management - basic governor of the process and system,

- Time - the performance management process, especially the performance appraisal is usually greatly constrained by time,

- Overall negative perception of the system and process due to various reasons by different levels of employees and management,

- Requires an on-going initiative and process,

- Objectivity of senior management,

- Basis of self-appraisal - voluntary or obligatory,

- The actual form/scorecard used for the appraisal inclusive of its contents, 
- Consistency in application,

- Alignment to strategy of the organisation including the mission and vision,

- Learning and development opportunities arising from the process,

- Technology used for performance management practices within the organisation,

- Feedback regarding performance - positive and negative feedback,

- Ethics and integrity involved and applied,

- Pay incentives linked to the performance management system and process - one of the most influential factors currently,

- Method of management of poor performers,

- Grievance procedure relevant to the performance management system within the organisation, etc.

\subsubsection{Performance Measure Factors}

Performance measure factors differ from the three preceding sections; it is more specific and somewhat technical in nature, as follows:

- Linked to performance goals,

- Performance measures are required to meet certain qualifying criteria in order to be effective,

- It is required to be specific,

- Of essential nature is the need for it to be measureable with regard to its outputs,

- Structured, realistic and attainable,

Linked to a time scale for effectiveness,

- Clearly defined goals,

- Should command a realistic level of stretch- links to effort required in order to be achieved,

- Individual objectives to be linked to objectives and strategy of the team, department/division, and organisation as a whole,

- Controllable by the individual to a reasonable extent,

- Valid with objective guidelines of expected performance,

- Performance objectives to be set, as far as is possible by someone, or group of people apart from the employee/ individual being assessed,

- All measures of performance to be mirrored by the system/scorecard.

It is evident that performance management is an area that requires much attention and in-depth focus. It may, at any time be influenced by various factors simultaneously and the management of these effects is what determines the outcome of its effectiveness.

\section{Research Methodology}

A primary source of data was used for the purpose of this literature. Face-to-face \& telephonic discussions/interviews' were conducted using a set questionnaire. Performance Management compliance audits were conducted on employees' Portfolios of Evidence (POE). POE files contain employee scorecards, PDPs \& evidence of work that has been completed relevant to content of the scorecard.

Questions were drawn up to create a questionnaire used for the face-to-face and telephonic discussions. An employee scorecard and PDP audit template was drawn up to conduct the performance compliance audit.

The population used to select the sample size was 220. This comprised employees from line management level to general staff members. The sample used was $35 \%$ of the total population. $N=78$ randomly selected full time operational staff members of various grades, races and ages across the Gauteng offices. All line management staff has been included in the process. An equal amount of staff members were selected from each of the Gauteng offices to comprise the 78 employee sample size.

The same sample was used for the discussions, and the performance audit, the research process was integrated.

The questionnaire comprised of 9 closed ended questions with the opportunity to comment. The discussion questionnaire comprised the following questions:

Q 1.Do you have a full understanding of the ePM system?

Q 2.Did you have a one on one discussion with your Team Leader/Manager? 
Q 3.Do you have a full understanding of your KPI's?

Q 4.From your perspective, are the KPI's achievable and have an impact on the target of the unit?

Q 5.Does the Team Leader/Manager and the member provide feedback and follow through on the development focus areas?

Q 6.Do you have a portfolio of evidence?

Q 7.Do you clearly understand what evidence you need to present?

Q 8.Is your PDP helping to equip yourself in your current role?

Q 9.Are you using the PDP to plan your long term career progression?

The performance management compliance audit contained the following:

The Audit template consisted of 3 sections \& 9 questions thereunder; covering scorecard compliance, performance reviews and PDPs.

\section{Data Analysis}

The findings of the discussions held with employees using the questionnaire are represented on the tables.

Table 1: Percentage representation of employee performance discussion question responses

\begin{tabular}{|c|c|c|c|}
\hline & \multicolumn{3}{|c|}{$\%$} \\
\hline & Yes & No & Total \\
\hline Q 1. Do you have a full understanding of the ePM system? & 36 & 64 & 100 \\
\hline Q 2. Did you have a one on one discussion with your Team Leader/Manager? & 100 & 0 & 100 \\
\hline Q 3. Do you have a full understanding of your KPI's? & 94 & 6 & 100 \\
\hline Q 4. From your perspective, are the KPI's are achievable and have an impact on the target of the unit? & 96 & 4 & 100 \\
\hline $\begin{array}{l}\text { Q 5. Does the Team Leader/Manager and the member provide feedback and follow through on the } \\
\text { development focus areas? }\end{array}$ & 71 & 29 & 100 \\
\hline Q6. Do you have a portfolio of evidence? & 97 & 3 & 100 \\
\hline Q 7. Do you clearly understand what evidence you need to present? & 92 & 8 & 100 \\
\hline Q 8. Is your PDP helping to equip yourself in your current role? & 27 & 73 & 100 \\
\hline Q 9. Are you using the PDP to plan your long term career progression? & 90 & 10 & 100 \\
\hline Average & 78 & 22 & 100 \\
\hline
\end{tabular}

Analysis of each question in Table 1, as well as associated comments:

Question 1: $36 \%$ of the sample indicated that they have a full understanding of the ePM system whereas $64 \%$ indicated that they do not. Comments included that the system is confusing due to being time sensitive, in-depth training has not been provided to team members when changes were made to the system, only line management was trained and information was not filtered through effectively. Employees stated that they sometimes become frustrated and despondent when experiencing system problems as the performance review and appraisal process is usually a stressful period.

Question 2: $100 \%$ of the sample had one-on-one discussions with their managers during the mid-year and $3^{\text {rd }}$ Quarter review and appraisal processes. This illustrates that compliance in terms of the performance review and appraisal processes is at its optimum.

Question 3: $94 \%$ indicated that a full understanding of KPIs. This reflects that the vast majority employees understand their jobs. $6 \%$ indicated that they do not possess a full understanding. Comments included that aspects of certain KPIs are not assessed according to the way the work is carried out and completed; clarity is required in this regard.

Question 4: $96 \%$ of sampled employees' believe that their KPIs are achievable and contribute to the targets of their unit. $4 \%$ believe that KPIs are not $100 \%$ achievable and don't have a direct impact on the units targets. Comments included that work done is not directly linked to KPIs and that the point of making a significant impact on the target of the unit is yet to be reached.

Question 5: $71 \%$ receive feedback and follow through on development focus areas, whereas $29 \%$ indicated that feedback and follow through was not adequate or did not exist at all. Employees commented that managers do not always provide adequate feedback, which resultantly hampers development. Follow through on development focus areas was the main concern among employees. 
Question 6: All sampled employees possess Portfolios of Evidence. This enforces the illustration of compliance to performance management processes.

Question 7: 91\% indicated the full understanding of evidence to be presented in the POEs whereas $9 \%$ do not possess a clear understanding. There is a direct correlation between employees that indicated a limited understanding of KPIs and an unclear understanding of evidence to be presented In the POE. Comments were similar to that of question 3 , and also included that some evidence is deemed irrelevant when performance reviews and appraisals are conducted.

Question 8: $27 \%$ of employees affirmed that PDPs assist in equipping them in their current role, whereas $73 \%$ stated that it does not. Employees commented that the PDP is merely a formality and is completed for compliance as a requirement of the POE. Training initiatives are minimal to almost non-existent at present within the division which severely limits development of employees. The online booking system for training has a 3 month window period and is usually fully booked. Most courses available company-wide are irrelevant to the division. The existence of a PDP without follow through is futile and causes demotivation amongst employees.

Question 9: 90\% of sampled employees conceded that PDPs are used for long term career progression as they as individuals are responsible for their careers - the PDP is simply used as a planning and documenting tool. External qualifications are listed as well as long term goals of individuals. 10\% indicated that the PDPs are not used, some due to de-motivation, others due to lack of confidence in the. Process.

Table 2: ePM Compliance Audit Results

\begin{tabular}{|c|c|c|c|c|}
\hline & & & & \\
\hline & Yes & No & $N / A$ & Total \\
\hline \multicolumn{5}{|l|}{ 1.Scorecard: OUTPUT Section - Compliance } \\
\hline 1.1 Is there more than one (1) Strategic Performance Objective listed on the Scorecard & 67 & 11 & 0 & 78 \\
\hline 1.2 Is there a signed scorecard by Manager in portfolio of evidence & 35 & 43 & 0 & 78 \\
\hline 1.3 Is there a signed scorecard by Staff Member in portfolio of evidence & 34 & 44 & 0 & 78 \\
\hline \multicolumn{5}{|l|}{ 2. Scorecard: Performance Review Sessions including Interim Performance Appraisals } \\
\hline 2.1 First Quarter Review occurred & 22 & 12 & 44 & 78 \\
\hline 2.2 Mid Year Review occurred & 76 & 1 & 1 & 78 \\
\hline 2.3 Third Quarter Review occurred & 54 & 24 & 0 & 78 \\
\hline $\begin{array}{l}2.4 \text { Is the Interim Performance Appraisal signed off by the employee and the Line } \\
\text { Manager (only applicable to staff who completed an Interim Performance Appraisal) }\end{array}$ & 34 & 1 & 43 & 78 \\
\hline \multicolumn{5}{|l|}{ 3. PDP } \\
\hline 3.1 is the PDP approved? & 63 & 15 & 0 & 78 \\
\hline 3.2 Is the PDP updated? & 57 & 21 & 0 & 78 \\
\hline Average Compliance & 49 & 19 & 10 & 78 \\
\hline
\end{tabular}

Analysis of Table 2 - ePM compliance audit results:

Section 1

1.1: 67 of the sampled employees are fully compliant in terms of the number of SPOs required on the scorecard whereas 11 employees are not.

$1.2 \& 1.3$ : These yielded similar figures with a difference of 1 individual. There is a direct correlation between the employees' whose managers have not signed scorecards and those who have not signed their own scorecards. There was also a difference between the number of filed scorecards and number of employees that did not have a scorecard in their files.

Section 2

2.1: Official Scorecard contracting had taken place after the $1^{\text {st }}$ quarter of the financial year, thus the majority classified as N/A - $1^{\text {st }}$ Quarter review sessions did not occur.

2.2: 76 sampled employees Mid-Year reviews occurred, there is 1 outstanding due to non-compliance to ePM timelines and the employee classified N/A was on maternity leave during the Mid-Year review period.

2.3: 54 sampled employees completed $3^{\text {rd }}$ Quarter reviews. The outstanding 24 had not completed their $3^{\text {rd }}$ Quarter reviews at the time of the Audit due to operational requirements - the third Quarter review was however, still in progress within the timelines. 
2.4: 35 Employees had Interim Appraisals conducted due to various reasons such as change in job requirements, change in roles within the organisation and specific development issues.

Section 3

3.163 sampled employees possessed approved PDPs whereas 15 employees had PDPs at different stages of completion, from non-existent to in progress to awaiting approval.

3.257 sampled employees possessed updated PDPs whereas 21 did not. The 15 sampled employees with unapproved PDPs formed part of the 21 employees who's PDPs were not updated.

\section{Recommendations}

Deductions of the analysis of the findings highlight the gaps and inconsistencies in the current performance management process and structure.

\subsection{Cultivating understanding with regard to the ePM System}

The understanding of the electronic performance management system is currently one of the most significant and dominant challenges facing employees within the organisation. In-depth training initiatives and assessments in the form of mock tests of the functionality and understanding of the system should be put in place on the various levels. Initially at organisational level, so as to create awareness at top level of the challenge that is faced at lower levels. The next target should be divisional level, followed by teams within divisions. If a fragmented lack of understanding is found within the organisation, training may be conducted on individual level.

When changes/developments to the ePM system are implemented, communication must be sent out and guidelines with specific information should essentially be included. Training sessions must be made available for those who may require it, dependant on the extent of the change. If the change is not significant enough to incur the cost of actual man to man training sessions online training may be used. The improved understanding of the systems might be impactful in that the employee outlook of the system may be transformed; this might have a positive impact on the performance management process at large and in turn employees may become accustom to a seamless process - this allows employees to focus on the more significant areas requiring attention and influence their behaviours positively.

\subsection{Increasing Compliance - ePM process timelines and Policy}

A gap in terms of the comprehensive compliance to the organisation's ePM policy and timelines is evident. Emphasis on the importance of the policy and timelines must be reiterated and filtered through from senior management level. Compliance checklists may be drawn up when conducting performance management activities such as performance reviews and appraisals. An all-inclusive policy pack, inclusive of Frequently Asked Questions may be sent out to employees. A dedicated HR representative from each division may be made available to answer any additional questions and provide expert advice when required. Employee perspectives towards performance management and policies on the whole may improve due to the increased concern regarding the accuracy and streamlined nature of the process and impacts being clarified - this may to a small extent modify employee behaviour in the Performance Management process.

Incentives may be granted additionally to improve compliance levels, such as an additional amount paid out to the employee with the annual performance bonus. Awards may be granted to the divisions that rank $1^{\text {st }}$ in terms of compliance and the employees within the division rewarded accordingly. This may also improve the competitiveness within the organisation at large and assist management in being assertive. The culture of the organisation may be impacted In that employees may feel part of a larger body than just immediate teams.

\subsection{Improving Feedback \& follow through regarding development areas}

Feedback regarding development areas during the Performance Management process as well as follow through on development was found as the most prevalent challenge facing employees. Feedback is an essential step in any performance management process. Measures such as creating an online platform for employees to concede when adequate feedback is provided by management as well as physical checklists and questionnaires may be developed to better manage the challenge. 
Follow through on development areas is linked to the effectiveness of the PDP. Majority of employees regard the PDP as irrelevant due to no follow through on training listed. Training plans for the division must be informed by business needs as well as the training listed on employee PDPs. Information regarding training availability stemming from the long and short term plans must be communicated with employees effectively on a continuous basis in order to change or at least alter the mind-set of employees in respect of training within the organisation.

Employees must be given guidelines on recommended training and also given freedom within boundaries to choose training interventions that they deem to be relevant to their current development needs within their roles and prospective roles. The online platform for booking and obtaining approval for training has recently been implemented. The system must be used for maximum effect for other employees and management. The training levels of divisions are also easily accessible by training personnel. Management may use the data from the system to measure how the changing focus to increased emphasis on employee training initiatives impacted the division on a short and long-term basis. Formal training is not the only avenue that may be explored. On the job training, mentoring and coaching is a very successful way of up-skilling staff in developmental areas they have. If done right, mentoring, coaching and even short term on the job training may have a better impact on employee performance than a formal training course would.

The incorporation of a mentoring/coaching/on the job training KPI may be added to the Scorecard in order to ensure that it is carried out within the organisation. The extent to which it makes an impact and adds value may also be determined by doing a comparative analysis on the data before and after introduction. Training and development in any organisation aids in moving the organisation from one point to the next in terms of skill base and capability if used appropriately. Training opportunities usually encourage employees to perform better and have and may have an indirect positive impact on their behaviour - this must also be considered during the performance management planning stage. Training should be granted due consideration and used as a leveraging technique for its employees and the organisation.

\section{Conclusion}

Certain aspects of the Performance Management system and process within the organisation are currently viewed and experienced as challenges by employees. The understanding of the electronic performance management system, compliance to the ePM timelines and Policy as well as feedback and follow through with regard to developmental areas of employees are among the greatest challenges.

Measures such as formal and online training sessions with regard to the ePM System, creating awareness and developing incentive schemes in terms of increasing compliance, obtaining employee responses with regard to performance management feedback given by management as well as exploring different types of training and development initiatives in order to address employee development areas are among the recommendations.

Performance Management within any organisation is a two-way process affecting both the organisation and employees, attention to the needs of both should be essentially considered and a mutually beneficial process be implemented, modified if necessary, and prudently maintained.

\section{References}

Balle, L. (2013). Effect of Performance Feedback on employees. Demand Media. [Online] Available: http://smalllbusiness.chron.com leffects-performance-feedback-employees-175.html [Retrieved on 02/02/2013].

Bann, R. M. (November 2009). Factors that influence Performance Management at a large refinery in the North-West Province. [Online] Available: http://dspace.nwu.ac.za/bistream/handle/10394/4309/bann_rm.pdf?...1 [Retrieved on 07/01/2013].

Bayat, R. F. (2011). Impact on the Productivity of Human Resources Management, Performance Evaluation. Australian Journal of Basic and Applied Sciences. 5(12)

Cornell University (2013) retrieved from www.hr.cornell.edu > .. > Individual and Organizational Effectiveness

Grobler, P., Warnich, S., Carrell, M.R., Elbert, N.F., Hatfield, R.D. (2006). Human Resources Management in South Africa. London: Thomson.

Jamil, N. (2005). Impact of the performance evaluation system on employee behaviour in the Marketing and human Resource departments of a foreign bank in Karachi. [Online] Available: http://www.yasni.com/nida+jamil/check+people [Retrieved on 10/02/2012].

Kehinde, J. S. (2011). Talent Management: Effect on organisational performance. Journal of Management Research. 4(2), 178-186. doi: 10.5296/jmr.v4i2.937

Miah, M. K., \& Hossan. C. G. (2012). Performance Management system in UK retail industry: A case study. Far east Journal of Psychology and Business. 7(2). 13-25.

Millmore, M., Lewis, P., Saunders, M., Thornhill, A., \& Morrow, T. (2007). Strategic Human Resources Management. Contemporary 
issues. England: Prentice Hall.

Moore, M. (2013). Employee performance Appraisal. Demand Media. [Online] Available: http://smallbusiness.chron.com/employeeperformance-appraisal-1962.html [Retrieved on 03/03/2013].

Nel, P., Werner, .A. Du Plessis, A., Ngalo, O., Poisat, P., Sono, T., Van Hoek, L., \& Botha, C. (2013). Human Resources Management. Cape Town: Oxford University Press.

Nel, P.S., van Dyk, P.S., Haasbroek, G.D., Schultz, H.B., Sono, T., \& Werner A. (2004). Human Resources Management. Cape Town: Oxford University Press.

Noe, R.A., Hollenbeck, J.R., Gerhart, B., \& Wright PM. (2013). Human Resources Management: Gaining a competitive advantage. New York: McGraw-Hill Irwin.

Rao, V.S.P. (2005). Human Resources management. New Delhi: Excel Books.

Rao, V.S.P. (2009). Organisational Behaviour. New Delhi: Excel Books.

Regis R. (2008). Strategic Human Resources Management and Development. New Delhi: Excel Books.

Ryan, T. (2013). how to Observe employee performance. [Online] Available: http://smallbusiness.chron.com/observe-employeeperformance-19393.html [Retrieved on 19/02/2013].

Stone, M. (2007). Six steps to effective Performance Management. [Online] Available: http://www/workinfo.com/articles /6steps_performance_management_108.htm [Retrieved on 16/01/2013].

Walker, A. G. (2007). Is performance Management as simple as ABC. T=D, 61(2), 54-57. 